\title{
Parental Reaction to the Diagnosis of their Child with Febrile Seizures
}

\author{
Artan Haruni ${ }^{1}$, Marsela Haruni ${ }^{2}$ \\ ${ }^{1}$ Policlynic of Specialties nr. 3 Tirana
}

\begin{abstract}
Seizures is widely considered a stigmatized condition. Anyway parents frequently will get familiarized with the situation as time passes by, and the support granted to them plays a very important part. Due to excessive fear and the preoccupation that accompanies the seizures, relatives will often require particular support and information. World wide web (internet) and brochures will have their role as well toward offering information and educating the families of patients suffering from epilepsy. Aim: To understand how parents are informed about Febrile Seizure, to be supported better, to know them better and avoid the feeling of fear and stigma that can cause this problem. Materials \&Methods: The study was conducted during the period from June 2009 to July November 2011. We analyzed 106 children with diagnosis Complex Febrile seizures. Children with Simple Febrile Seizure were excluded from the study. Were interviewed parents of these children and analyzed their way of reacting to the recognition that the diagnosis of the child, the response to treatment side effects and resources from which they receive information. Results: $83 \%$ of parents feel bad because their child was with Febrile Seizures . 40\% of parents feel "shocked" when presented to diagnosis, $35 \%$ feel "sad", 15\% were "neutral", 6\% feel "relieved". $4 \%$ "no idea". Parents understand the diagnosis in different ways. $20 \%$ of parent feel "calm", $22 \%$ "fear", 38\%"unsure", 18\% “adopted", 2\% "without hope". 80\% of parents were concerned about "adverse effects" before the start of treatment with antiepileptic drug. 82\% feels good with "correct diagnosing and treatment". Sources of information and support regarding this disease for parents include Internet 39\%, medical staff $41 \%$, leaflets $7 \%$, and various support group $3 \%$, nothing $10 \%$. $40 \%$ of parents had been informed about the management of convulsive seizures, $60 \%$ had no information. $45 \%$ of children they had at least one parent with a university education, $55 \%$ of children had parents low and middle degree of education. Conclusion: Fear and anxiety are feelings to often experienced by parents of children with Febrile Seizures. Seizures are still widely viewed as a stigmatized condition as is underlined by negative initial reaction of parents who often are adopted over time because the support that was given. Because of the excessive fear and concern that is accompanying this diagnosis, families seeking a high level of information and support. Internet and leaflets play a key role in supplying information and education of their families.
\end{abstract}

Keywords: Febrile seizure, epilepsy, stigma.

Abbreviations: AED - Antiepileptic

\section{Introduction}

Febrile seizure is the most common type of seizure in children under 5 year. They are still subject of interest between pediatricians about the way of treatment. Although generally they are considered benign, they are extremely upsetting to the parents, because the high rate of recurrence. The American Academy of Pediatrics (1999) recommends no treatment for children with a simple febrile seizure. Regarding Complex Febrile Seizures sill there is a dilemma, to treat or no treat with antiepileptic (AED) prophylaxis. That dilemma because in one hand we know side effects of AED but in other hand the discussion is about the risk of prolonged febrile seizure cause to the brain. The animal data suggest that a seizure lasting 20 minutes can produce long-lasting physiological changes [13].

Since ancient times seizures were accompanied by stigma. Despite progress in medicine nowadays, unfortunately their diagnosis has yet profound impact on social and psychological in patients and their families due to lack of information

A parent reacts in different manner when he learn his child has Febrile Seizure. Their reactions include; fear, sadness, worry and underestimation in e few cases.

In our study we would like to determine parental reaction when they learn diagnosis of Febrile Seizure for their children, usage of antiepileptic treatment and understanding of the disease.

\section{Aim}

To understand how parents are informed about Febrile Seizure, to be supported better, to know them better and avoid the feeling of fear and stigma that can cause this problem.

\section{Materials \& Methods}

The present prospective study was conducted during the period from June 2009 to July November 2011.We analyzed 106 children with diagnosis Complex Febrile seizures. Children with Simple Febrile Seizure were excluded from the study.

Exclusion criteria of the study:

- Children with simple febrile seizure.

- Children who had made earlier afebrile seizures

- Children with abnormal neurologic examination.

- Children with abnormal brain imaging data.

- Children CNS infection.

We classified as Complex febrile seizure children with the following features (Commission 1993): (1) partial onset or focal features during the seizure, (2) prolonged duration $>15$ 


\section{International Journal of Science and Research (IJSR) \\ ISSN (Online): 2319-7064 \\ Index Copernicus Value (2013): 6.14 | Impact Factor (2014): 5.611}

minutes [14-15] or (3) recurrent febrile seizures within 24 hours of the first episode [16].

In our study we analyzed several factors: age, positive family history for febrile seizure, type of seizures, the reaction of parents to the confrontation with the diagnosis, reaction to the treatment with antiepileptic drug.

During the interview we asked parents to describe their reaction immediately after the news on the diagnosis with Febrile Seizures and early treatment for their child with AED. It assessed the level of understanding and comfort in terms of diagnosis and treatment with antiepileptic drug. Besides the data collected were used and other sources of support and information.

\section{Results}

Age of the 106 patients included in the study was 3-60 months. The highest number of patients were male 61/106 (57.5\%) and 45/106 (42.5\%) female. 22,6\% of patients have reported positive family history of febrile seizures. $30.2 \%$ resulting in abnormal EEG data. Partial seizure in 90(84.9\%) of patients and generalized seizures in 16(15.1\%)

$83 \%$ of parents feel bad because their child was with Febrile Seizures. The initial reaction from the moment they learn the diagnosis ranged from "shocked", "sad", "relieved", "no idea". $40 \%$ of parents feel "shocked" when presented to diagnosis, $35 \%$ feel "sad", 15\% were "neutral", 6\% feel "relieved". 4 \% "no idea". Parents understand the diagnosis in different ways. $20 \%$ of parents feel "calm", $22 \%$ "fear", $38 \%$ "unsure", 18\% "adopted" and 2\% "without hope".

$80 \%$ of parents were concerned about "adverse effects" before the start of treatment with antiepileptic. Sources of information and support regarding this disease for parents include Internet 39\%, medical staff $41 \%$, leaflets $7 \%$, and various support group3\%, nothing $10 \%$.

$40 \%$ of parents had been informed about the management of convulsive seizures, $60 \%$ had no information.

$45 \%$ of children they had at least one parent with a university education, 55\% of children had parents low and middle degree of education.

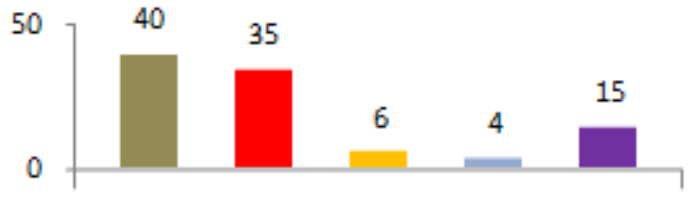

"Shocked " Sad $\mid$ "Releived $\mid$ No idea " Neutral

Figure 1: Parental reaction in the begining

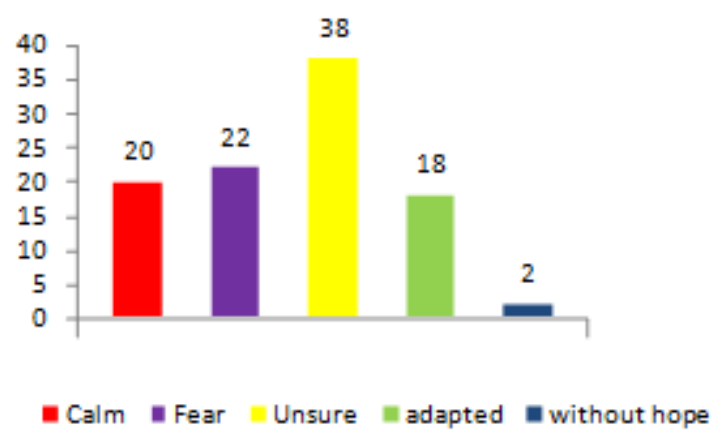

Figure 2: Understanding the diagnosis

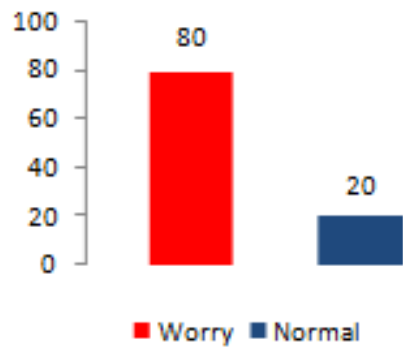

Figure 3: How parents feel regarding AED adverse effects

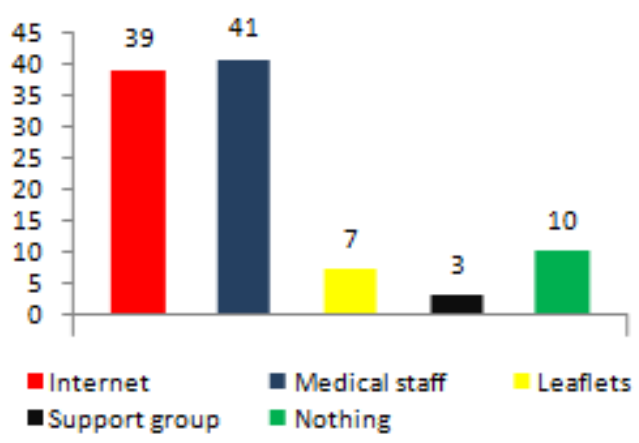

Figure 4: Information sources for the parents

\section{Discussion}

Although we live in modern times there is still lack of information and regarding seizures [1-4]. Fears that children with febrile convulsions can pass Epilepsy is an worry for the parents. If we compare the attitude of the public in relation to persons with epilepsy to those with spastic cerebral palsy or mental health problems, people with epilepsy feel more refused $[1,3,5]$.

Parents appear as a key point of the because of the reaction they manifests reaction after their child is diagnosed with Febrile Seizure will determine how the child will interpret this parental reaction and will manifest psychologically. When the parental reaction is negative, the children taught with the thought that seizures are something embarrassing [4, 5-7].

$83 \%$ of the parents had negative initial reaction to the diagnosis of febrile convulsions and $45 \%$ still continue to feel this way. Parents are often concerned on the use of antiepileptic medication in their children. The main concern has to do with the side effects of these drugs on the child's development in learning as well as their duration. 


\section{International Journal of Science and Research (IJSR) \\ ISSN (Online): 2319-7064 \\ Index Copernicus Value (2013): 6.14 | Impact Factor (2014): 5.611}

In his study Bower was referred to the concern of parents for the child with epilepsy. These concerns had to do with the nature of the seizure, the effects of treatment, cause of the seizure, damages that may come from crises or their effect in relation to intelligence, mental health or social problems. Austin, in his study he found that parental concern and fear was focused towards the treatment and management of illness $(6,8,10)$.

Educating parents about the disease can help them to better manage their child's disease. This could lead to the parents to accept the illness more easily, to avoid fear to her, to know how to fight them.

Sufficient information is important to educate and improve the attitude of public opinion to seizures and epilepsy. Information obtained from the Internet can play an important role in disseminating this information. Other sources of information such as leaflets can play an important role in disseminating this information.

\section{Conclusion}

Fear and anxiety are often experienced by parents of children with seizures. Parents often are uninformed regarding seizure management.

Furthermore it has to do with the educational level of parents and sources of information. The consequences of the seizures and the possible side effects of antiepileptic used are the main cause of persistent fears that parents can experience.

Seizures still widely viewed as a stigmatized condition as is underlined by negative initial reaction of parents who often are adopted over time because the support that was given. Because of the excessive fear and concern that is accompanying this diagnosis, families seeking a high level of information and support. Internet and leaflets play a key role in supplying information and education of their families.

\section{References}

[1] Baumer JH, David TJ, Valentine SJ, Roberts JE, Hughes BR. Many parents think their child is dying when having a first febrile convulsion. Dev Med Child Neurol. 1981;23(4):462-4.

[2] Balslev T. Parental reactions to a child's first febrile convulsion. Acta Paediatr Scand. 1991;80:466-9. [PubMed]

[3] Forsgren L. Incidence and prevalence. In: Wallace S, Farrell K, editors. Epilepsy in Children. 2nd ed. London: Arnold, 2004.

[4] Duncan JS. Antiepileptic drugs and the electroencephalogram. Epilepsia. 1987;28(3):259-66.

[5] Davies, R., Davis, B. \& Sibert, J. (2003) Parents' stories of sensitive and insensitive care by paediatricians in the time leading up to and including diagnostic disclosure of a life-limiting condition in their child.

[6] Huang MC, Liu CC, Huang CC. Effects of an educational program on parents with febrile convulsive children. Pediatr Neurol. 1998;18:150-5. [PubMed]
[7] Ostrom KJ, Schouten A, Kruitwagen CLJJ, Peters ACB, Jennekens Schinkel A. Parents' perceptions of adversity introduced by upheaval and uncertainty at the onset of childhood epilepsy. Epilepsia 2001

[8] Rugg-Gunn, F. J., N. A. Harrison, et al. Evaluation of the accuracy of seizure descriptions by the relatives of patients with epilepsy. Epilepsy Res 2001;43(3):193-9.

[9] Starke, M. \& Moller, A. (2002) Parents' needs for knowledge concerning the medical diagnosis of their children. Journal of Child Health Care, 6, 245-257., 29, 77-83.

[10] Shore CP, Austin JK, Dunn DW. Maternal adaptation to a child' sepilepsy. Epilepsy Behav 2004; 5: 557-68.

[11] Van Stuijvenberg M, de Vos S, Tjiang GCH, Steyerberg EW, Derkson-Lubson G, Moll HA. Parents' fear regarding fever and febrile seizures. Acta Paediatr. 1999;88:618-22. [PubMed]

[12] Wakamoto H, Nagao H, Hayashi M, Morimoto T. Longterm medical, educational, and social prognoses of childhood-onset epilepsy: a population-based study in a rural district of Japan. Brain Dev 2000; 22:246-55.

[13] Toth, Z., Yan, X. X., Haftoglou, S., Ribak, C. E., and Baram, T. Z. (1998). Seizure-induced neuronal injury: Vulnerability to febrile seizures in immature rat model. J. Neurosci. 18, 4285-4294.

[14]Berg, A. T., and Shinnar, S. (1996). Complex febrile seizures. Epilepsia 37, 126-133.

[15] Nelson, K. B., and Ellenberg, J. H. (1976). Predictors of epilepsy in children who have experienced febrile seizures. N. Engl.]. Med. 295, 1029-1033.

[16] Annegers, J. E, Hauser, W. A., Shirts, S. B., and Kurland, L. T. (1987). Factors prognostic of unprovoked seizures after febrile convulsions. N. Engl. J. Med. 316, 493-498. 